\title{
Analysis of Non-Uniform Expansion Behavior of Injected EVA
}

\author{
Ferreir a $\mathrm{EJ}^{1}$, Dias $\mathrm{MM}^{2}$ and Schneider $\mathrm{EL}^{2 *}$ \\ ${ }^{1}$ Academic of the Mechanical Engineering Course of the University Feevale, Brazil \\ ${ }^{2}$ Institute of Exact Sciences and Technologies, Feevale University, Brazil
}

Submission: July 18, 2018; Published: August 14, 2018

*Corresponding author: Schneider EL, Institute of Exact Sciences and Technologies, Feevale University, Brazil, Tel: +55 5135868800 ; Email: eduardoluis@feevale.br

\begin{abstract}
Currently the sports footwear market is very competitive, in which it is sought to produce products that provide high performance, using technology in the production processes as well as in the materials used. One of the main materials used in the composition of soles and midsole of these products is EVA (Ethylene-Vinyl Acetate), which brings several benefits such as cost reduction, comfort, lightness and softness. The injection molding process is the most efficient for obtaining EVA soles, however, EVA undergoes large expansions that may vary according to its formulation and geometry of the desired model. The objective of this work is to analyze the non-uniform deformation of EVA, used in the injection molding processes, as well as one method used to correct such distortions that occur in the expansion of this material. For this, a bibliographic review was carried out to analyze the chemical composition of the EVA, whose composition will determine the characteristics of expansion and softness. The work also addresses the steps of the injection process by analyzing the temperatures and pressure employed and an analysis of how to predict and correct the distortion in EVA expansion. It is proposed to use a section of a 3D model, where it is determined where compensations should be applied and using 3D modeling software.
\end{abstract}

To analyze the generation of smaller bubbles in less thick regions of an EVA sole, a scanning electron microscope (SEM) analysis was performed. In addition, the measurements of the analyzed model were compared with the virtual model through a 3D scan. Hardness tests on the Asker C scale and injection simulations were also performed to analyze the cooling time of the part after leaving the mold, volumetric contraction that occurs in the extraction of the mold part, and the thicknesses of the walls of the product. The results indicate that the comparison of the models was within the accepted tolerance, which allows a variation in the expansion of up to $1 \mathrm{~mm}$ in the length of the evaluated points. From the analyzes made in the scanning electron microscope and in the hardness test, it was possible to verify that in regions of smaller thickness and smaller volume, the EVA blend cannot have its total expansion, i.e., micro bubbles of gases generated in the expansion are smaller in these regions when compared to regions of greater volume and thickness. Consequently, these regions become denser and less soft. Simulations indicated that in regions where bubbles do not expand, there is also an early cooling of the material when compared to regions with higher volume, proving that the cooling time is directly linked to the EVA expansion rate.

Keywords: EVA; IMEVA; Expansion; Midsole; Sole; Shoe; Footwear; Mold design; Mold injection

Abbreviations: EVA: Ethylene-Vinyl Acetate; SEM: Scanning Electron Microscope

\section{Introduction}

With increasing global competitiveness, the search for new materials that provide higher-quality, better-designed products that increase production efficiency are critical for companies that want to stay competitive. Many manufacturers of sports shoes have adopted EVA injected as the main component in soles and midsole, as this material allows to make light, soft and cheap sneakers. However, the EVA requires some care and some procedures must be adopted to obtain injected parts of good quality. EVA has the capacity to expand from 30\% to $90 \%$ its size and there is great difficulty in predicting how this expansion occurs due to non-uniformity in the expansion process.

This article analyzes the non-uniform behavior of EVA expansion and some methods used to correct this deformation.
Through years of experience and with the aid of 3D modeling software, compensations are applied at certain points of the product, according to the geometry, to try to predict the behavior of the material. In order to obtain the EVA (Ethylene-Vinyl Acetate) that is molded in the injection process, it is necessary to make a mixture to acquire a compound that will determine the characteristics of expansion and softness of the material, for the formulation of the compound we can have the following types of raw materials [1]:

a. Resins: It is the base of the blend. Generally, the EVA resin is mixed with LDPE and elastomers depending on the desirable properties;

b. Expanders: These are organic or inorganic compounds 
that, by the action of heat, decompose to generate solid and gaseous byproducts of diverse nature, thus being responsible for the expansion process;

c. Activators: They are catalysts, decrease the decomposition temperature of the blowing agent, thus avoiding the degradation of the polymer matrix;

d. Cross-linking agents: They are responsible for forming crosslinks in the polymer, increasing dimensional stability, chemical resistance, heat stability, and stiffness of the compound;

e. Lubricants: They are substances that decrease the friction between the polymer chains facilitating the processing and decreasing any interaction of the polymer mass with the equipment used;

f. Plasticizers: These are liquid substances with high boiling points and low molecular weight. When added to a polymer, they increase the flexibility and softness of the product. In the processing of EVA foams the aromatic plasticizers are the most used;

g. Pigments: Organic and inorganic compounds responsible for coloring the foams, influence the expansion of the material. In EVA you can pigment with different colors.

h. Loads: These are insoluble solids which are added to the polymers during processing in amounts sufficient to decrease the final cost or to change some of their physical properties in a controlled manner.

\section{Eva Injection Molding Process}

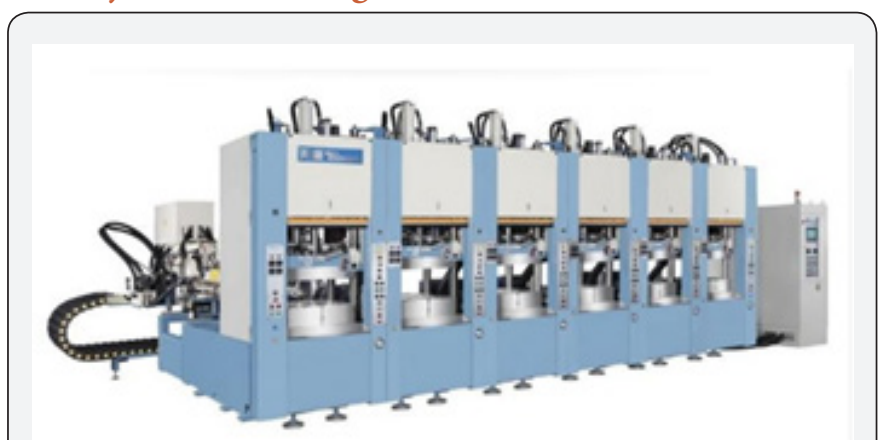

Figure 1: Six-station EVA injection machine from manufacturer Tienkang [2].

After blending to form the EVA compound for injection is completed, the material is taken to an injector that can be rotating or with stations aligned according to Figure 1. The justification for adopting a machine with many stations is given by the fact of the average injection cycle of each mold is high, around 7 minutes, so with a multi-station machine you can achieve a faster and more efficient production.

Below the steps of the injection process [3]:

(a) The mixture is added to the injector storage tank. (b) The injection volume is calculated and adjusted according to the mold.

(c) The material is heated to $95^{\circ} \mathrm{C}$ and injected into the mold at a pressure of $\sim 1200$ bar.

(d) The mold is heated to $170{ }^{\circ} \mathrm{C}$ to activate the expander and also the crosslinking agents

(e) The mold is kept closed at $170{ }^{\circ} \mathrm{C}$ until the crosslinks are fully completed, about $1.5 \mathrm{~min} / \mathrm{mm}$ thick.

(f) The mold is opened, and the EVA sole jumps out of the cavity rapidly and begins to expand.

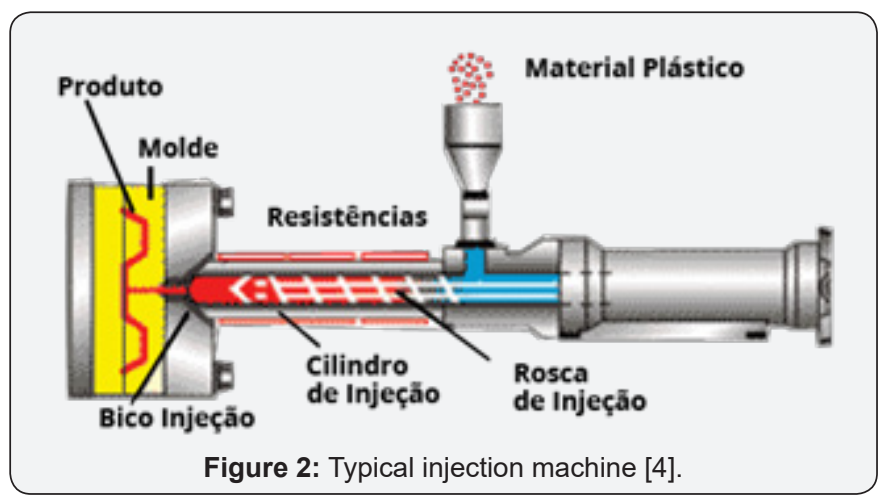

Injection in a typical injection machine can be observed in Figure 2. In order to obtain an EVA midsole or midsole injected into the appropriate dimensions, we must follow a few steps, where through experience in this type of product, we know in which points we should apply the compensations to correct the subsequent distortion in the EVA expansion.

First, we must have our 3D model defined, from there we follow the next steps:

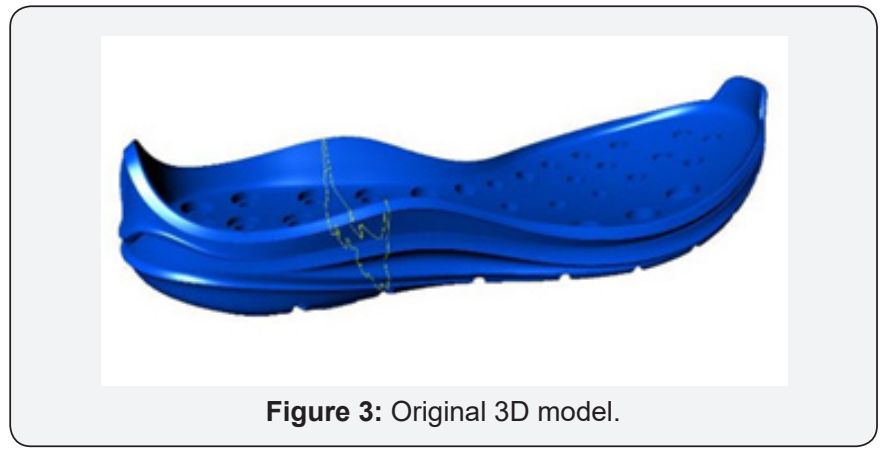

- To demonstrate the steps, we will use a section of an example 3D model, as in Figure 3.

- The 3D modeling software called Rhinoceros [5], geometry deformation tools were used to compensate for the points of interest (Figure 4 \&5).

After the compensations, the general expansion factor was applied, which is reprinted in Figure 6 by the blue line, which can vary from $30 \%$ to $90 \%$, depending on the formulation of the EVA blend, this factor was applied reducing the size of the model. 

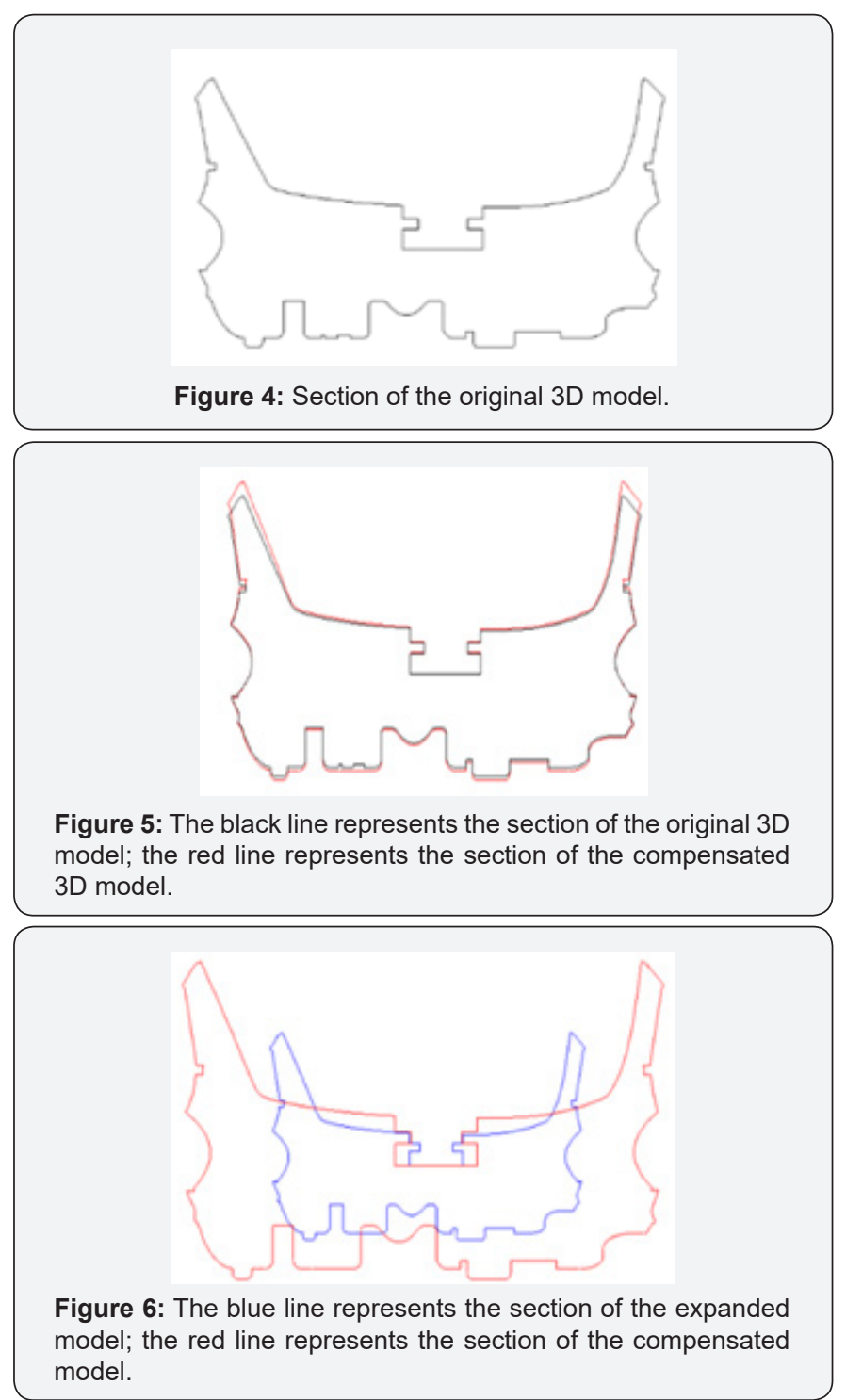

After the compensions $o$ and the general expansion factor were applied, as it was a model for aluminum casting, a further $1.2 \%$ was also applied to compensate the contraction of the aluminum. If it were a completely milled mold, there was no need to compensate for the shrinkage of the aluminum.

Analysis and Results

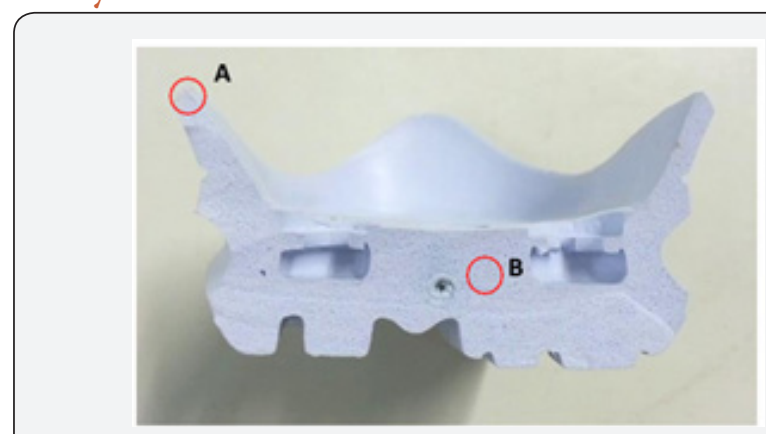

Figure 7: Tip A and B analyzed

To verify the generation of smaller bubbles in less thick regions, a cross section was cut from an eva sole, so an analysis can be performed in the electron scanning microscope (SEM) of
Feevale University, comparing images at points A and B (Figure $7 \& 8$ ) of the same product, with increases of 50x and 100x. Figure 9 shows the analysis at point B, made in SEM with a 100 -fold increase, we can clearly observe the formation of larger bubbles when compared to Figure 10, which represents point A and this with the same increase of 100 times.

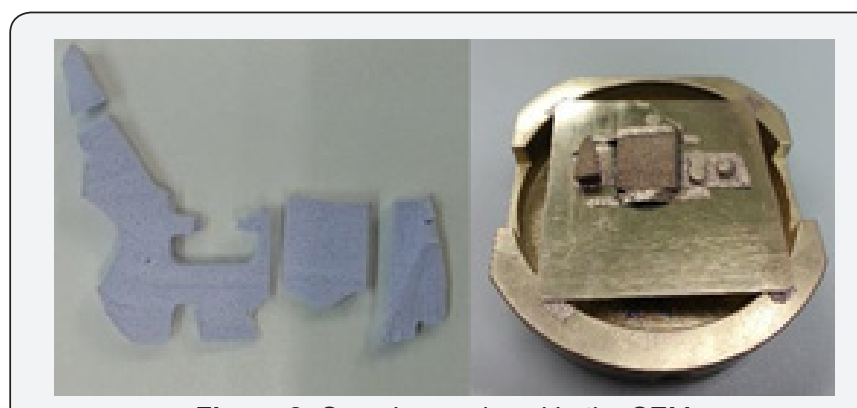

Figure 8: Samples analyzed in the SEM
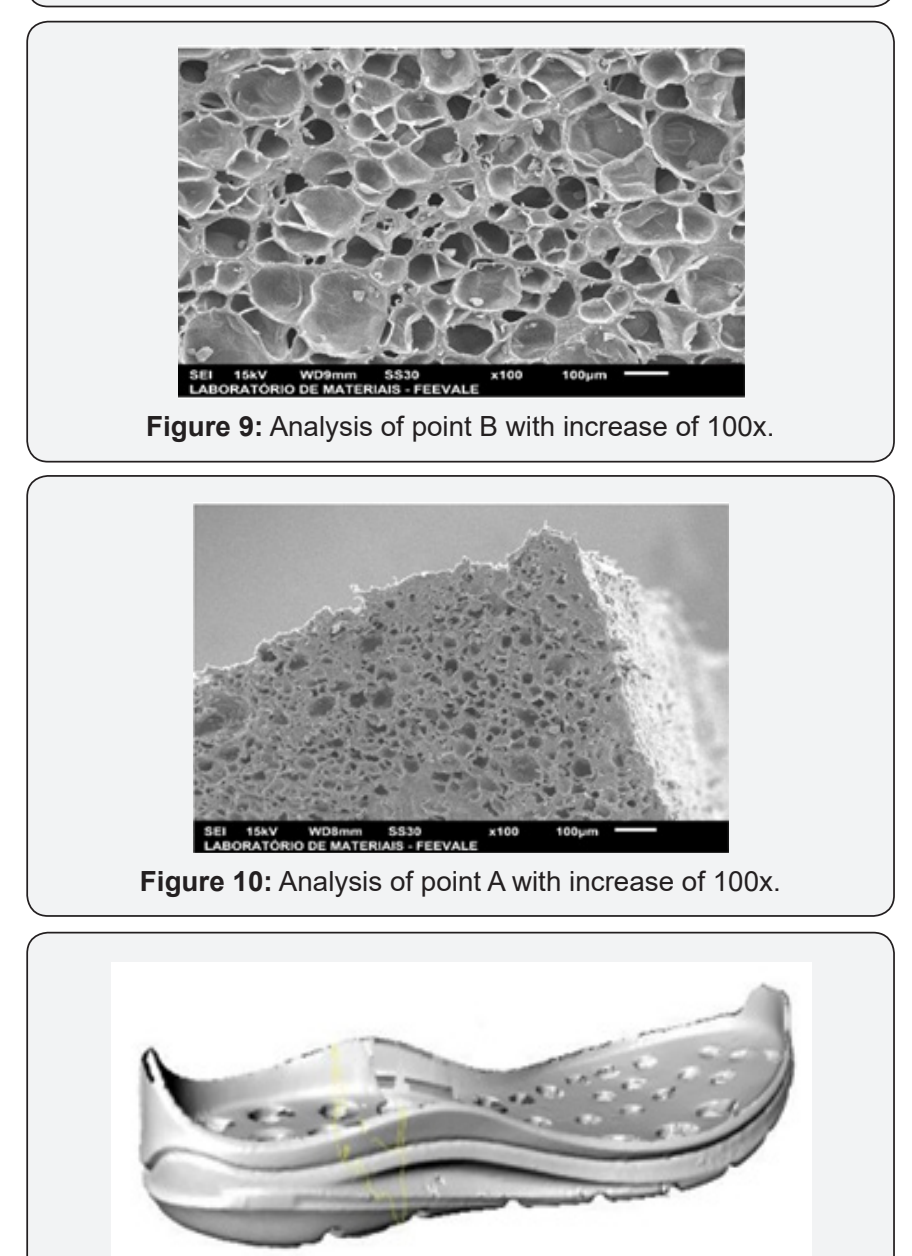

Figure 11: Scanning of the sole

To verify if the analyzed model reached the desired measurements, the original virtual model was compared with a 3D scanning, this was done in a 3D scanner, model Infinite 2.0, of the manufacturer Cimcore (Figure 11\&12) [6].

The result of the comparison of the models was within the accepted tolerance, which allows a variation in the expansion of up to $1 \mathrm{~mm}$ in the length of the points in question. This 
comparison can be seen in Figure 13, where the black line represents the original 3D mole and the red line represents a scan of the injected EVA sole.

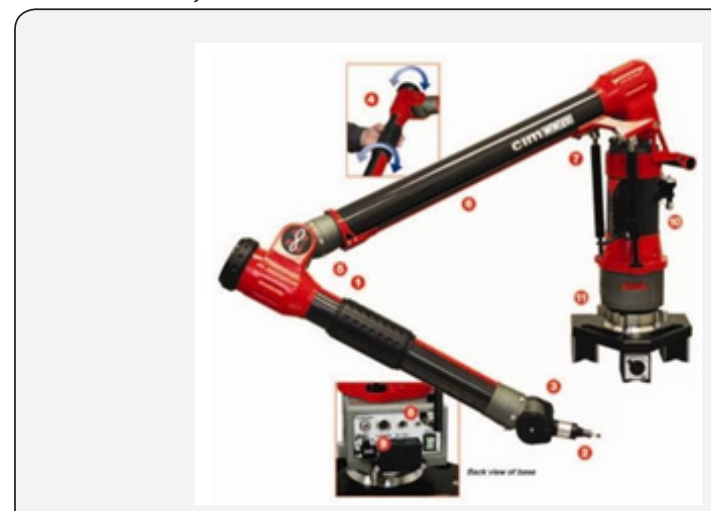

Figure 12: Cimcore brand 3D scanner.
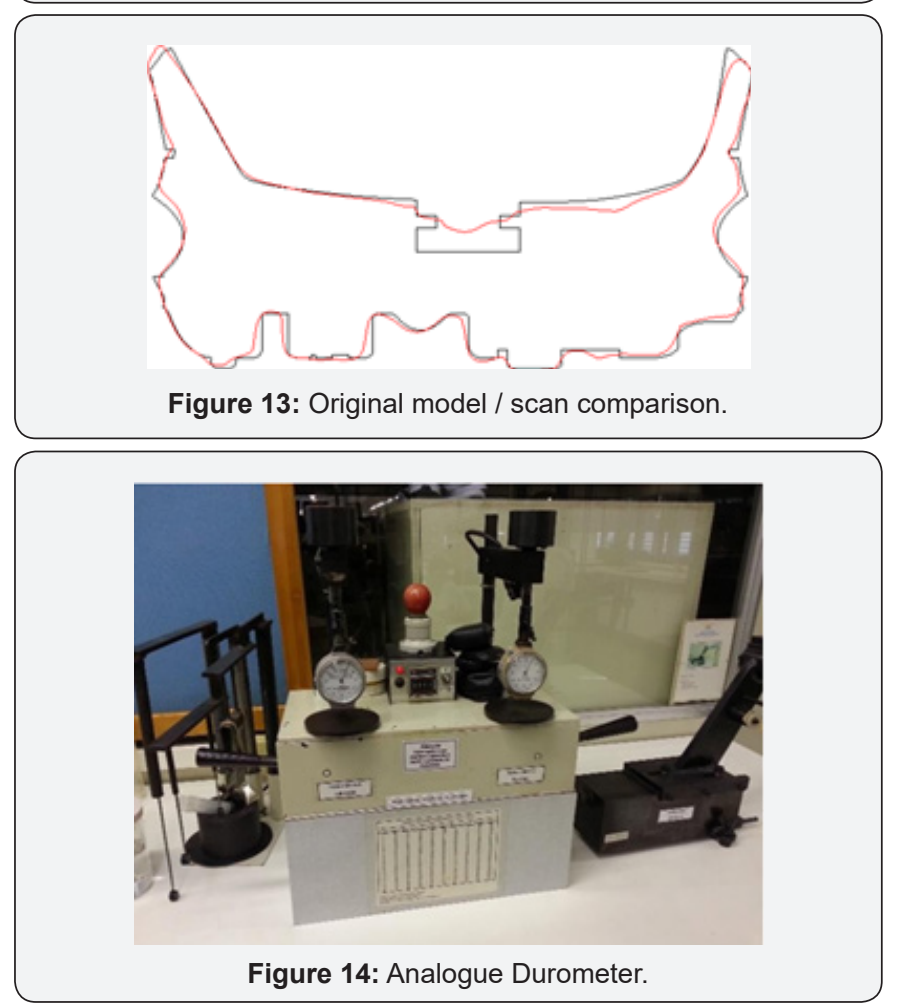

Also, for points $\mathrm{A}$ and $\mathrm{B}$ were made hardness tests using the Asker $C(A / C)$ scale, with an analogue durometer and $5 \mathrm{~mm}$ spherical tip (Figure 14). For comparison purposes, the two samples were prepared with $3 \mathrm{~mm}$ thickness and an average of 3 results were made. The average hardness found at point $A$ was $58 \mathrm{~A} / \mathrm{C}$ and at point $\mathrm{B}$ was $44 \mathrm{~A} / \mathrm{C}$

Injection simulations were performed in Autodesk Moldflow Adviser software [7], where it was possible to perform several analyzes, such as:

a. Variation of the cooling time of the part after leaving the mold, Figure 15.

b. Volumetric contraction occurring in the extraction of the mold part, Figure 16. c. Thickness of the product walls, Figure 17.
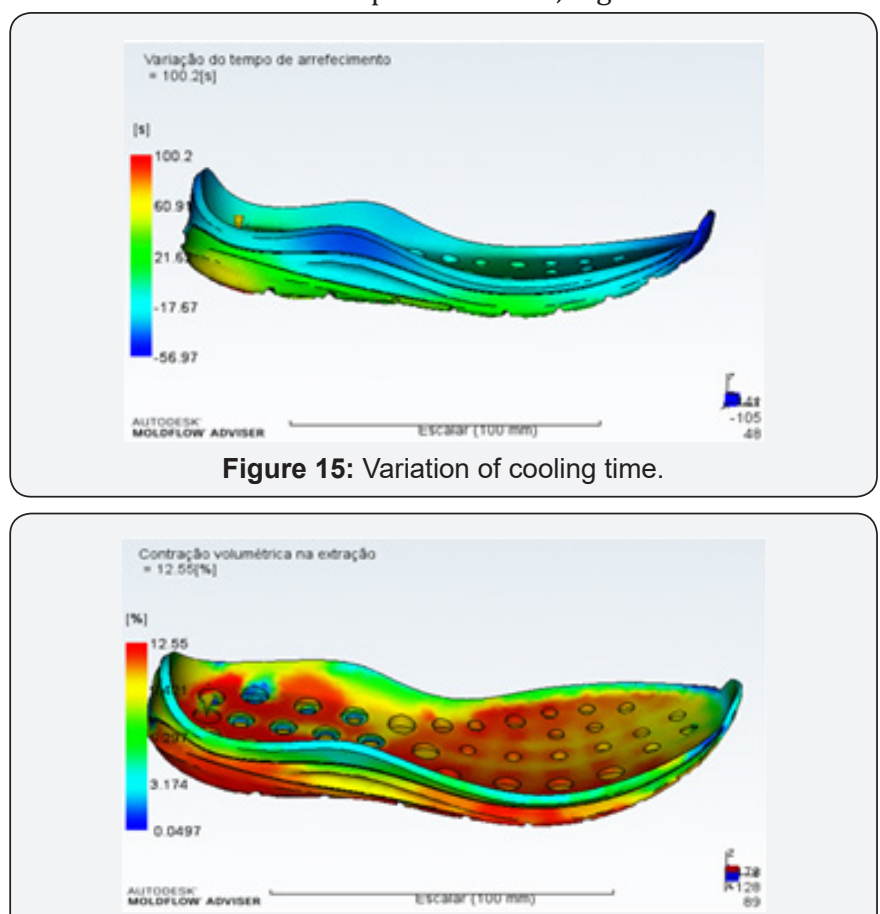

Figure 16: Volumetric shrinkage in the extraction.

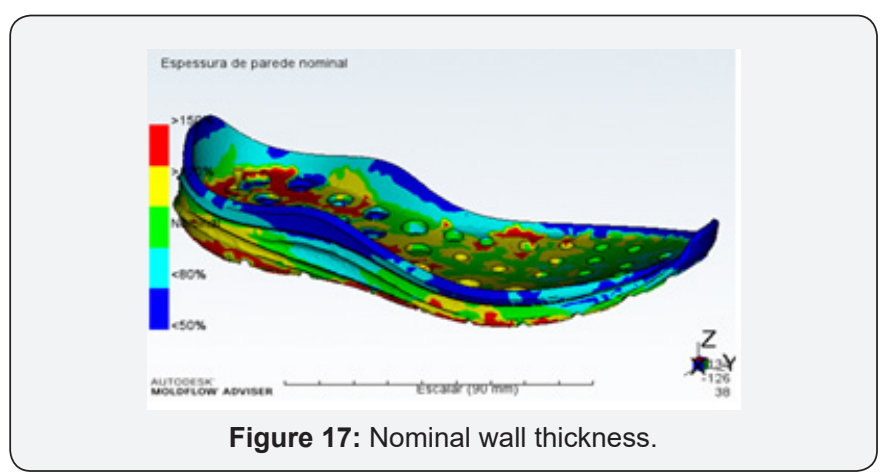

Final Considerations

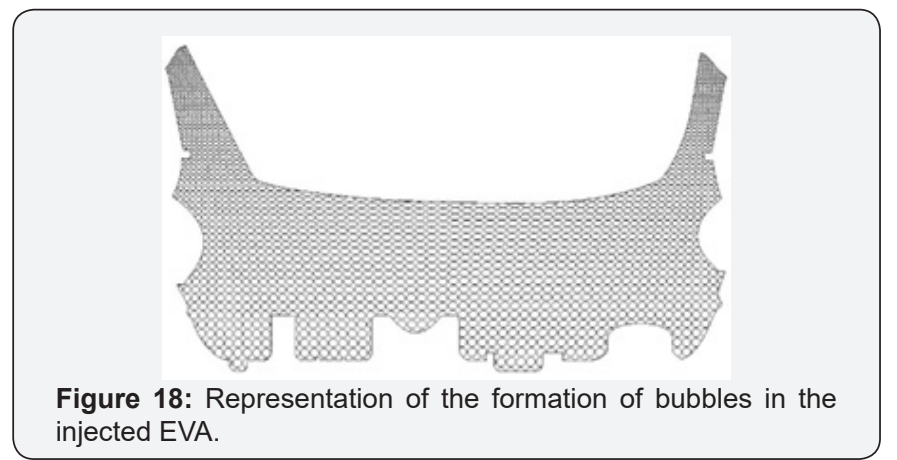

From the analyzes made in the scanning electron microscope and in the hardness test, it was possible to prove that in regions of smaller thickness and lower volume the EVA blender expander cannot have its total expansion, that is, the micro bubbles of gases generated at the moment of expansion are smaller in these regions when compared with regions of greater volume and thickness, consequently these regions become denser and less tender. This directly influences the final geometry of the product 
Figure 18. The compensation methods to correct the distortion of the EVA parts work satisfactorily within the tolerance, however they cannot predict all cases of distortions, since the models generally present varied and complex forms. Simulations done in Autodesk Moldflow Adviser [7], demonstrated that in these regions where the bubbles do not expand, there is also an early cooling of the material, when compared to regions of higher volume, thus proving that the cooling time of the material is directly linked to the EVA expansion rate.

\section{References}

1. ALPIRE-CHÁVEZ, M (2002) Apostila of Expanded Materials. Course Discipline, Plastic Technician. SENAI / CIMATEC. Salvador, BA.

DOI: 10.19080/AJOP.2018.01.555569
2. http://www.tienkang.com.tw

3. Allena RD, Newmana ST, Mitchella SR, Templea RI, Jones CL, et al. (2005) Design of experiments for the qualification of EVA expansion characteristics. Robotics and Computer-Integrated Manufacturing 21(4-5): 412-420.

4. http://www.tecplasplasticos.com.br/servicos.html/

5. http://www.tienkang.com.tw

6. http://go.hexagonmi.com/cimcore

7. AUTODESSK INC., McInnis Parkway, San Rafael, CA 94903 - USA

\section{Your next submission with Juniper Publishers will reach you the below assets}

- Quality Editorial service

- Swift Peer Review

- Reprints availability

- E-prints Service

- Manuscript Podcast for convenient understanding

- Global attainment for your research

- Manuscript accessibility in different formats

( Pdf, E-pub, Full Text, Audio)

- Unceasing customer service

Track the below URL for one-step submission https://juniperpublishers.com/online-submission.php 